\title{
Materiais usados na constituição dos principais componentes de células a combustível de óxido sólido
}

\author{
(Materials used in the manufacture of the main components \\ of solid oxide fuel cells)
}

\author{
A. C. Nascimento, N. D. S. Mohallem \\ Departamento de Química, Instituto de Ciências Exatas, Universidade Federal de Minas Gerais - UFMG \\ Av. Antônio Carlos 6627, Belo Horizonte, MG 31270-901
}

\begin{abstract}
Resumo
As células a combustível de óxido sólido (SOFC) são dispositivos capazes de gerar energia elétrica com alta eficiência e baixa emissão de poluentes. As altas temperaturas de operação dessas células (600 a $\left.1000{ }^{\circ} \mathrm{C}\right)$ são benéficas no sentido de possibilitar a reforma in situ do combustível utilizado, bem como sua aplicação em sistemas de co-geração de energia, aumentando sua eficiência teórica total que pode chegar entre 80 e $85 \%$. Entretanto, essas altas temperaturas, o contato direto entre materiais de constituições químicas diferentes e a utilização de gases redutores e oxidantes, são alguns dos fatores que impõem severas restrições aos materiais usados na preparação de seus principais componentes. O presente artigo tem como objetivo revisar o desenvolvimento do estado da arte, com relação aos materiais de ânodo, cátodo, eletrólito, interconectores e selantes, usados em SOFCs. Os requisitos necessários para o bom funcionamento de cada componente e os materiais que melhor se adequam aos mesmos são descritos. As vantagens e desvantagens dos principais materiais encontrados na literatura são também comentadas e comparadas.
\end{abstract}

Palavras-chave: células a combustível de óxido sólido, ânodo, cátodo, eletrólito.

\begin{abstract}
Solid oxide fuel cells (SOFC) are devices capable to generate electricity with high efficiency and low emission of pollutants. The high operation temperatures of these batteries $\left(600\right.$ to $\left.1000^{\circ} \mathrm{C}\right)$ are advantageous, making possible the reform of the fuel used in situ as well as its application in systems for cogeneration of energy, increasing its total efficiency up to values between 80 and $85 \%$. However, these high temperatures require severe restrictions on the materials used in the preparation of their main components. This paper aims to review the state of the art of the developed material as anode material, cathode, electrolyte, interconnects and seals, to be used in SOFCs. The requirements for a good operation of each component and the materials that best fit their specific need are described. The advantages and disadvantages of the main materials found in the literature are discussed and compared. Keywords: solid oxide fuel cells, anode, cathode, electrolyte.
\end{abstract}

\section{INTRODUÇÃO}

As células a combustível de óxido sólido (SOFC) são dispositivos eletroquímicos capazes de converter, de forma direta, energia química em energia elétrica com alta eficiência e baixa emissão de poluentes [1,2]. Estas células têm se mostrado altamente promissoras como fontes de "energia limpa", pois as emissões de $\mathrm{CO}_{2}$ são extremamente baixas quando da utilização de combustíveis que possuam carbono em sua composição. Suas partes constituintes são fixas operando livre de ruídos, tornando-as viáveis para uso doméstico, podendo também ser utilizadas em aplicações industriais, estações de geração de eletricidade e até mesmo em veículos automotores [1].

Cada célula unitária de uma célula é constituída basicamente de um eletrólito denso em contato direto de dois eletrodos porosos, denominados de ânodo e cátodo.
Devido a sua elevada densidade o eletrólito é impermeável aos gases que são difundidos nesses eletrodos, impedindo que eles se misturem.

Nessas células, o gás combustível é continuamente alimentado no ânodo enquanto o oxigênio, do ar,é alimentado no cátodo [3]. Nesse último o oxigênio é reduzido a íons $\mathrm{O}^{2-}$, segundo a reação [4]:

$$
1 / 2 \mathrm{O}_{2}(\mathrm{~g})+2 \mathrm{e}^{-} \cdot \mathrm{O}^{2-}
$$

No eletrodo oposto (ânodo) o combustível é oxidado liberando elétrons conforme a reação seguinte:

$$
\mathrm{H}_{2}(\mathrm{~g})+\mathrm{O}^{2-} \cdot \mathrm{H}_{2} \mathrm{O}(\mathrm{g})+2 \mathrm{e}^{-}
$$

A reação global, acompanhada por liberação de calor, pode ser escrita da seguinte forma: 


$$
\mathrm{H}_{2}(\mathrm{~g})+1 / 2 \mathrm{O}_{2}(\mathrm{~g}) \cdot \mathrm{H}_{2} \mathrm{O}
$$

As reações A, B e C são observadas nas células, independentemente dos gases combustíveis (hidrogênio, hidrocarbonetos, etanol e metanol) e oxidantes $\left(\mathrm{O}_{2}\right.$ ou ar) utilizados. O rendimento da reação global não é de $100 \%$ e a energia liberada na forma de calor ajuda a manter a temperatura de funcionamento dessas células e conseqüentemente da célula. A Fig. 1 apresenta o esquema de funcionamento da célula unitária de uma célula a combustível de óxido sólido (SOFC)

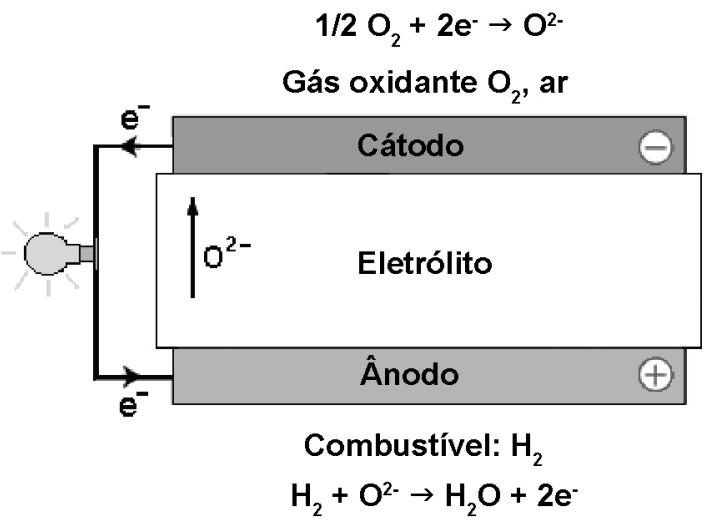

Figura 1: Esquema do funcionamento de uma SOFC.

[Figure 1: Scheme of the operation of a SOFC.]

Nestes sistemas, materiais cerâmicos são utilizados na constituição tanto dos eletrodos quanto do eletrólito, e são submetidos a uma faixa de temperatura que pode variar de 600 a $1000{ }^{\circ} \mathrm{C}$ [1]. As altas temperaturas de operação permitem que haja reforma in situ do combustível que pode ser constituído de hidrocarbonetos leves, com cadeias carbônicas situadas entre o metano $\left(\mathrm{CH}_{4}\right)$ e a nafta, metanol
$\left(\mathrm{CH}_{3} \mathrm{OH}\right)$ e etanol $\left(\mathrm{C}_{2} \mathrm{H}_{5} \mathrm{OH}\right)$. Nos casos em que o hidrogênio $\left(\mathrm{H}_{2}\right)$ é utilizado não são necessárias etapas de reforma. As eficiências elétricas obtidas por essas células estão em torno de 45 a $60 \%$. A energia térmica gerada pode ser aproveitada para fazer funcionar uma turbina e a eficiência teórica total (elétrica e térmica) pode chegar a 85\% [1-5].

Os principais componentes das células unitárias que formam uma SOFC são: ânodo, cátodo, eletrólito, interconectores e selantes. Os materiais que constituem esses componentes são cerâmicos, metálicos ou vitrocerâmicos, sendo necessário que os mesmos possuam um comportamento de expansão térmica bem ajustado, compatibilidade química e estabilidade em atmosfera redutora e oxidante. No entanto, as elevadas temperaturas de operação dessas células, entre outros fatores, podem trazer algumas complicações, havendo a necessidade de uma boa compatibilidade física e química entre os materiais com os quais são produzidos esses componentes, visando reduzir problemas como fadiga térmica e corrosão [1].

Esse artigo tem como objetivo produzir uma revisão bibliográfica a respeito dos materiais utilizados na produção do ânodo, cátodo, eletrólito, interconectores e selantes de uma célula a combustível de óxido sólido.

\section{Principais materiais usados na constituição do ânodo}

O ânodo tem a função de fornecer os sítios onde ocorrem as reações eletroquímicas de oxidação catalítica do gás combustível com os íons $\mathrm{O}^{2-}$ vindos do cátodo. Esse eletrodo é também capaz de fornecer as trajetórias para que os elétrons sejam transportados do sítio de reação na interface ânodo/eletrólito para os interconectores da SOFC [6].

Existem alguns requisitos que devem ser atendidos para que o ânodo permaneça estável durante o funcionamento da célula. Entre eles podemos citar: condutividade elétrica, alta atividade eletrocatalítica, ser estável em atmosfera redutora, ser fino o bastante para evitar perdas por transferência de

Tabela I - Materiais usados na produção do ânodo [7].

[Table I - Materials used in the production of anode [7].]

\begin{tabular}{|c|c|c|c|c|c|}
\hline $\begin{array}{c}\text { Materiais à } \\
\text { base de níquel }\end{array}$ & & $\begin{array}{l}\text { hulas químicas } \\
\text { resentativas }\end{array}$ & $\begin{array}{l}\text { Materiais à base de } \\
\text { cobre }\end{array}$ & $\begin{array}{c}\text { Materiais à base de } \\
\text { lantânio }\end{array}$ & $\begin{array}{c}\text { Outros tipos de } \\
\text { materiais }\end{array}$ \\
\hline $\mathrm{NiO} / \mathrm{YSZ}$ & YSZ & $\begin{array}{l}\left(\mathrm{ZrO}_{2}\right)_{1-\mathrm{x}}\left(\mathrm{Y}_{2} \mathrm{O}_{3}\right)_{\mathrm{x}} \\
\quad(x \sim 0,08-0,1)\end{array}$ & $\mathrm{CuO}_{2} / \mathrm{CeO}_{2} / \mathrm{YSZ}$ & $\mathrm{La}_{1-\mathrm{x}} \mathrm{Sr}_{\mathrm{x}} \mathrm{CrO}_{3}$ & $\mathrm{CeO}_{2} / \mathrm{GDC}$ \\
\hline $\mathrm{NiO} / \mathrm{SSZ}$ & SSZ & $\begin{array}{l}\left(\mathrm{ZrO}_{2}\right)_{\mathrm{x}}\left(\mathrm{Sc}_{2} \mathrm{O}_{3}\right)_{1-\mathrm{x}} \\
\quad(x \sim 0,8)\end{array}$ & $\mathrm{CuO}_{2} / \mathrm{YSZ}$ & $\mathrm{La}_{1-\mathrm{x}} \mathrm{Sr}_{\mathrm{x}} \mathrm{Cr}_{1-\mathrm{y}} \mathrm{M}^{*} \mathrm{O}_{3}$ & $\mathrm{TiO}_{2} / \mathrm{YSZ}$ \\
\hline $\mathrm{NiO} / \mathrm{GDC}$ & GDC & $\begin{array}{c}\mathrm{Ce}_{\mathrm{x}} \mathrm{Gd}_{1-\mathrm{x}} \mathrm{O}_{\mathrm{y}} \\
(x \sim 0,8 / y \sim 1,8)\end{array}$ & $\mathrm{CuO}_{2} / \mathrm{CeO}_{2} / \mathrm{SDC}$ & & \\
\hline $\mathrm{NiO} / \mathrm{SDC}$ & SDC & $\begin{array}{c}\mathrm{Ce}_{x} \mathrm{Sm}_{1-\mathrm{x}} \mathrm{O}_{\mathrm{y}} \\
(x \sim 0,8 / y \sim 1,9)\end{array}$ & & & \\
\hline $\mathrm{NiO} / \mathrm{YDC}$ & YDC & $\begin{array}{c}\mathrm{Ce}_{\mathrm{x}} \mathrm{Y}_{1-\mathrm{x}} \mathrm{O}_{\mathrm{y}} \\
(x \sim 0,8 / y \sim 1,96)\end{array}$ & & & \\
\hline
\end{tabular}


massa, ter porosidade entre 20 e $40 \%$, ter coeficiente de expansão térmica compatível com os demais componentes e ser capaz de promover reações de reforma interna dependendo do combustível utilizado. [7]. A Tabela I mostra uma lista de materiais que podem ser usados na produção do ânodo.

O ânodo produzido a partir do NiO/YSZ (YSZ: zircônia estabilizada com ítria a $8 \% \mathrm{em} \mathrm{mol}$ ) é o mais comumente usado [8], devido seu baixo custo, sua estabilidade em atmosfera redutora mesmo em altas temperaturas, além de seu coeficiente de expansão térmica ser bastante próximo daqueles dos demais componentes da SOFC. Nesse material o níquel atua como um excelente catalisador nas reações de reforma e eletrocatalisador nas reações de oxidação eletroquímica do combustível. O níquel é também responsável pela condutividade elétrica dentro do ânodo.

A YSZ constitui a estrutura ou "esqueleto" onde as partículas de Ni estão dispersas, impedindo que elas venham a se aglomerar durante o processo de operação da SOFC. O níquel e a YSZ são imiscíveis e não reativos em uma faixa muito ampla de temperatura. Essa característica permite que a preparação do composto $\mathrm{NiO} / \mathrm{YSZ}$ seja realizada por processos convencionais de sinterização seguida de redução na presença de um gás combustível, formando um cermet (compósito metal-cerâmico) de Ni/YSZ. Essas reações de redução ocorrem durante o início do período de operação da SOFC [6].

Tem-se demonstrado extensivamente que o desempenho do ânodo de Ni/YSZ é dependente da quantidade de níquel e também de sua microestrutura [9]. Os fatores responsáveis pela microestrutura do ânodo incluem o tamanho recíproco dos grãos de Ni e YSZ, e da distribuição das partículas de Ni na matriz de YSZ [10]. A Fig. 2 apresenta uma ilustração da interface ânodo/eletrólito, onde é possível visualizar a chamada região de contato triplo (TPB) onde a YSZ, o níquel e o gás combustível interagem entre si possibilitando a ocorrência das reações de oxidação do combustível. Nela as esferas claras correspondem a moléculas do gás combustível e as azul escuro aos íons $\mathrm{O}^{2-}[7]$.

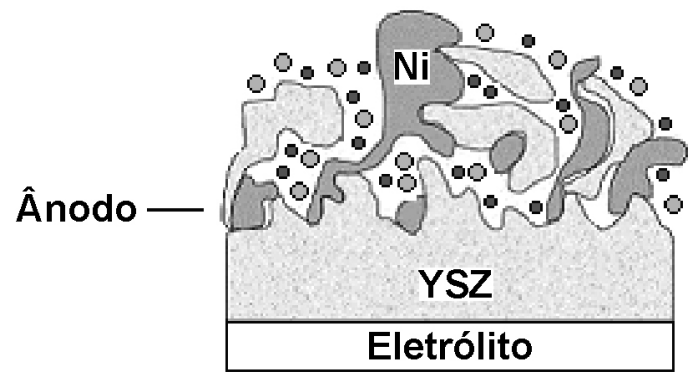

Figura 2: Região de contato triplo (TPB) em um ânodo constituído de Ni/YSZ.

[Figure 2: Triple-phase-boundary (TPB) in an Ni/YSZ anode.]

No entanto, apesar de ser amplamente utilizado, o ânodo contendo Ni é responsável por alguns problemas de incompatibilidade com eletrólitos que apresentam lantânio em sua composição [11]. Outro problema está relacionado à atividade eletrocatalítica do Ni na oxidação eletroquímica do hidrogênio, que pode ser prejudicada quando gás natural ou metano é utilizado diretamente como combustível, devido à deposição de carbono sobre as partículas de Ni. O problema toma dimensões maiores quando são utilizados hidrocarbonetos com alta massa molar, pois nesses casos essa deposição ocorre muito rapidamente [12]. Quando o metano é utilizado, altas razões de vapor de água/carbono são capazes de suprimir essa reação de deterioração. As equações abaixo demonstram o efeito do vapor água na minimização do problema [6].

$$
\begin{aligned}
& \mathrm{CH}_{4}(\mathrm{~g}) \cdot \mathrm{C}(\mathrm{g})+2 \mathrm{H}_{2}(\mathrm{~g}) \\
& \mathrm{CH}_{4}(\mathrm{~g})+\mathrm{H}_{2} \mathrm{O}(\mathrm{g}) \cdot \mathrm{CO}(\mathrm{g})+3 \mathrm{H}_{2}(\mathrm{~g})
\end{aligned}
$$

Na reação D houve formação de carbono, na reação $\mathrm{E}$ vemos a formação do $\mathrm{CO}$ devido à presença do vapor de água. Infelizmente, esse efeito não é possível para combustíveis com alta massa molar, sendo necessária uma pré-reforma com vapor ou com oxigênio [12].

Outra forma de diminuir o efeito da deposição de carbono é o emprego de ânodos de YSZ dopados com óxido de cobre $\left(\mathrm{CuO}_{2}\right)$ [7]. No entanto o baixo ponto de fusão desse composto (aproximadamente $1235^{\circ} \mathrm{C}$ ) e a baixa atividade catalítica do mesmo nas reações de oxidação direta do gás combustível comprometem sua utilização no ânodo de células a combustível de óxido sólido [13].

Dos ânodos constituídos a partir de óxidos de lantânio, a cromita de lantânio dopada com estrôncio $\left(\mathrm{La}_{1-\mathrm{x}} \mathrm{Sr}_{\mathrm{x}} \mathrm{CrO}_{3}\right)$ apresenta boa estabilidade em atmosferas redutoras e oxidantes a altas temperaturas e o $\mathrm{La}_{1-\mathrm{X}} \mathrm{Sr}_{\mathrm{x}} \mathrm{Cr}_{1-\mathrm{y}} \mathrm{M}_{\mathrm{y}} \mathrm{O}_{3}$ demonstra boa atividade catalítica na reforma do metano [12].

Além do níquel, do cobre e do lantânio, o ânodo também pode ser produzido com óxidos de cério e titânio. Materiais como o $\mathrm{CeO}_{2} / \mathrm{GDC}$ são capazes de atingir $470 \mathrm{~mW} \cdot \mathrm{cm}^{-2} \mathrm{a}$ $1000^{\circ} \mathrm{C} . \mathrm{O} \mathrm{CeO}_{2}$ exibe boa condutividade iônica e eletrônica em atmosfera redutora. No entanto, esse material apresenta variação no número de oxidação do $\mathrm{Ce}\left(\mathrm{Ce}^{4+}\right.$ para $\left.\mathrm{Ce}^{3+}\right)$. Essa variação ocorre com liberação de oxigênio produzindo deformações da rede cristalina, levando ao aparecimento de trincas que prejudicam a estabilidade mecânica do eletrodo [14]. $\mathrm{O} \mathrm{TiO}_{2} / \mathrm{YSZ}$, apesar de aumentar a resistência mecânica do ânodo, provoca uma queda na sua condutividade devido à presença do titânio [7].

Dentre todos os materiais estudados até hoje, com o objetivo de serem empregados como ânodo de SOFCs, o composto $\mathrm{NiO} / \mathrm{YSZ}$ é sem dúvida, o que tem sido mais amplamente utilizado por apresentar os melhores resultados [15].

\section{Principais materiais usados na constituição do cátodo}

O cátodo é o eletrodo onde o oxigênio puro ou do ar 
Tabela II - Alguns dos materiais usados na produção do catodo [18-20].

[Table II - Some of the materials used in the production of cathode.]

\begin{tabular}{|c|c|c|c|c|c|c|c|}
\hline $\begin{array}{c}\text { Materiais } \\
\text { baseados } \\
\text { no } \\
\text { lantânio }\end{array}$ & $\begin{array}{c}\text { Fórmula } \\
\text { química } \\
\text { representativa }\end{array}$ & $\begin{array}{c}\text { Materiais } \\
\text { baseados } \\
\text { no } \\
\text { estrôncio }\end{array}$ & $\begin{array}{c}\text { Fórmula } \\
\text { química } \\
\text { representativa }\end{array}$ & $\begin{array}{c}\text { Materiais } \\
\text { baseados } \\
\text { no } \\
\text { gadolínio }\end{array}$ & $\begin{array}{c}\text { Fórmula } \\
\text { química } \\
\text { representativa }\end{array}$ & $\begin{array}{c}\text { Materiais } \\
\text { baseados } \\
\text { no ítrio }\end{array}$ & $\begin{array}{c}\text { Fórmula } \\
\text { química } \\
\text { representativa }\end{array}$ \\
\hline LSM & $\begin{array}{l}\mathrm{La}_{1-x} \mathrm{Sr}_{\mathrm{x}} \mathrm{MnO}_{3} \\
\quad(\mathrm{x} \sim 0,2)\end{array}$ & SSC & $\begin{array}{c}\mathrm{Sm}_{\mathrm{x}} \mathrm{Sr}_{1-\mathrm{x}} \mathrm{CoO}_{3} \\
\quad(\mathrm{x} \sim 0,5)\end{array}$ & GSC & $\begin{array}{c}\mathrm{Gd}_{1-x} \mathrm{Sr}_{\mathrm{x}} \mathrm{FeO}_{3} \\
\quad(\mathrm{x} \sim 0,2)\end{array}$ & YSCF & $\begin{array}{c}\mathrm{Y}_{1-\mathrm{x}} \mathrm{Sr}_{\mathrm{x}} \mathrm{Co}_{\mathrm{y}} \mathrm{Fe}_{1-\mathrm{y}} \mathrm{O}_{3} \\
(\mathrm{y}=0,7 / \mathrm{x} \sim 0,3-0,8)\end{array}$ \\
\hline LSF & $\begin{array}{l}\mathrm{La}_{1-\mathrm{x}} \mathrm{Sr}_{\mathrm{x}} \mathrm{FeO}_{3} \\
\quad(\mathrm{x} \sim 0,2)\end{array}$ & NSC & $\begin{array}{c}\mathrm{Nd}_{\mathrm{x}} \mathrm{Sr}_{1-\mathrm{x}} \mathrm{CoO}_{3} \\
\quad(\mathrm{x} \sim 0,8)\end{array}$ & GSM & $\begin{array}{l}\mathrm{Gd}_{1-\mathrm{x}} \mathrm{Sr}_{\mathrm{x}} \mathrm{MnO}_{3} \\
\quad(\mathrm{x} \sim 0,3-0,6)\end{array}$ & YCCF & $\begin{array}{l}\mathrm{Y}_{1-\mathrm{x}} \mathrm{Ca}_{\mathrm{x}} \mathrm{Co}_{\mathrm{y}} \mathrm{Fe}_{1-\mathrm{y}} \mathrm{O}_{3} \\
(\mathrm{x}=0,2 / \mathrm{y} \sim 0,1-0,7)\end{array}$ \\
\hline LSCF & $\begin{array}{c}\mathrm{La}_{1-\mathrm{x}} \mathrm{Sr}_{\mathrm{x}} \mathrm{Co}_{1-\mathrm{y}} \mathrm{Fe}_{\mathrm{y}} \mathrm{O}_{3} \\
\quad(\mathrm{x} \sim 0,4 / \mathrm{y} \sim 0,2)\end{array}$ & $\mathrm{BSCCu}$ & $\mathrm{Bi}_{2} \mathrm{Sr}_{2} \mathrm{CaCu}_{2} \mathrm{O}_{8}$ & & & $\mathrm{YBCu}$ & $\mathrm{YBa}_{2} \mathrm{Cu}_{3} \mathrm{O}_{7}$ \\
\hline
\end{tabular}

é reduzido a íons $\mathrm{O}^{2-}$ dentro de cada célula unitária. Em células que operam a baixas temperaturas, esse eletrodo é freqüentemente uma resistência limitante por causa do seu sobrepotencial, que é usualmente muito maior do que os sobrepotenciais anódicos.

Para que esse eletrodo possa apresentar um bom desempenho é necessário que sejam atendidas exigências como: alta condutividade eletrônica,compatibilidade química com o eletrólito, interconectores e selantes, estabilidade em atmosfera oxidante e alta condutividade iônica $[13,16]$.

O comportamento dos materiais que constituem o cátodo é muito dependente da temperatura, forma dos grãos, microestrutura e processos de deposição. A escolha do material apropriado depende principalmente do material cerâmico do eletrólito e da temperatura de operação da célula, lembrando que esse eletrodo é uma estrutura porosa que deve viabilizar uma rápida transferência de massa tanto para reagentes quanto para produtos gasosos [17].

A Tabela II mostra os materiais a partir dos quais o cátodo pode ser produzido, bem como suas respectivas fórmulas químicas.

Entre esses materiais, a manganita de lantânio dopada com estrôncio (LSM), a ferrita de lantânio dopada com estrôncio (LSF) e a cobaltita de samário dopada com estrôncio (SSC) são mais comumente empregadas na fabricação deste eletrodo. No entanto, a LSMé a mais popular desses compostos e a mais utilizada em células que operam a altas temperaturas como as SOFCs. Isso ocorre devido à compatibilidade existente entre o coeficiente de expansão térmica desse material e o coeficiente de expansão térmica do eletrólito (geralmente composto por YSZ). Além disso, a LSM possui alta estabilidade e alta atividade catalítica nas reações de redução do oxigênio em temperaturas acima de $800{ }^{\circ} \mathrm{C}$. Em temperaturas inferiores, no intervalo de 600 a $800{ }^{\circ} \mathrm{C}$, eletrólitos cerâmicos alternativos podem ser utilizados. Entre eles podemos citar a LSF e a ferrita cobaltita de lantânio dopada com estrôncio (LSCF) [7].

Quando o cátodo é constituído pela LSM ou por outros compostos, que possuam lantânio em sua composição, a compatibilidade com o eletrólito de YSZ é de suma importância, visto que a LSM é capaz de reagir com a YSZ em temperaturas acima de $1300{ }^{\circ} \mathrm{C}$ [21].

Materiais a base de estrôncio, gadolínio e ítrio são pouco utilizados devido a problemas de incompatibilidade química com o eletrólito e interconectores [7].

Assim a LSM tem se destacado como o material mais apropriado para ser utilizado como cátodo de células a combustível de óxido sólido [22].

\section{Principais materiais usados na constituição do eletrólito}

O eletrólito é o componente responsável pela condução do íon oxigênio $\left(\mathrm{O}^{2-}\right)$ que migra do cátodo para o ânodo, onde reage com o gás combustível gerando corrente elétrica. Os materiais de eletrólito utilizados em SOFCs devem apresentar entre suas principais propriedades: elevada condutividade iônica não permitindo a migração de elétrons do ânodo para o cátodo, estabilidade química mesmo a altas temperaturas e em atmosfera oxidante e redutora, impermeabilidade gasosa e coeficiente de expansão térmica próximo ao dos eletrodos [7]. A Tabela III mostra os principais materiais empregados na preparação do eletrólito.

Entre os materiais mais usados na fabricação do eletrólito podemos citar: a zircônia estabilizada com ítria (YSZ), a céria dopada com gadolínio (GDC) e o galato de lantânio dopado com estrôncio e magnésio (LSGM) [22].

No entanto, dentre estes, o que tem mostrado melhores resultados é a YSZ. Isso ocorre devido sua boa estabilidade química em relação aos demais componentes da célula [26].A ítria $\left(\mathrm{Y}_{2} \mathrm{O}_{3}\right)$ tem dois papéis principais: estabilizar a estrutura cúbica da zircônia e formar vacâncias de oxigênio. A alta condutividade iônica da YSZ é atribuída à formação dessas vacâncias [14]. A incorporação da ítria na rede cristalina da zircônia pode ser descrita por uma reação de defeitos (equação F), utilizando-se a notação de Kröger-Vink:

$$
\mathrm{Y}_{2} \mathrm{O}_{3} \cdot 2 \mathrm{Y}_{\mathrm{Zr}}{ }^{\prime}+3 \mathrm{O}_{\mathrm{o}}{ }^{\mathrm{x}}+\mathrm{V}_{\mathrm{o}} \cdot
$$


Tabela III - Materiais empregados na fabricação de eletrólitos usados em SOFCs [23-25].

[Table III - Materials used in the manufacture of electrolytes used in SOFCs [23-25].]

\begin{tabular}{|c|c|c|c|c|c|}
\hline $\begin{array}{c}\text { Materiais } \\
\text { baseados } \\
\text { no } \\
\text { zircônio }\end{array}$ & $\begin{array}{l}\text { Fórmula } \\
\text { química } \\
\text { representativa }\end{array}$ & $\begin{array}{c}\text { Materiais } \\
\text { baseados } \\
\text { no cério }\end{array}$ & $\begin{array}{c}\text { Fórmula } \\
\text { química } \\
\text { representativa }\end{array}$ & $\begin{array}{c}\text { Materiais } \\
\text { baseados } \\
\text { no } \\
\text { lantânio }\end{array}$ & $\begin{array}{l}\text { Fórmula } \\
\text { química } \\
\text { representativa }\end{array}$ \\
\hline YSZ & $\begin{array}{l}\left(\mathrm{ZrO}_{2}\right)_{1-\mathrm{x}}\left(\mathrm{Y}_{2} \mathrm{O}_{3}\right)_{\mathrm{x}} \\
(x \sim 0,08-0,1)\end{array}$ & GDC & $\mathrm{Ce}_{0,9} \mathrm{Gd}_{0,1} \mathrm{O}_{1,95}$ & LSGM & $\begin{array}{l}\mathrm{La}_{\mathrm{x}} \mathrm{Sr}_{1-\mathrm{G}} \mathrm{Ga}_{\mathrm{y}} \mathrm{Mg}_{1-\mathrm{y}} \mathrm{O}_{3} \\
\quad(x \sim 0,9 / y \sim 0,8)\end{array}$ \\
\hline SSZ & $\begin{array}{l}\left(\mathrm{ZrO}_{2}\right)_{\mathrm{x}}\left(\mathrm{Sc}_{2} \mathrm{O}_{3}\right)_{1-\mathrm{x}} \\
\quad(x \sim 0,8)\end{array}$ & SDC & $\begin{array}{c}\mathrm{Ce}_{\mathrm{x}} \mathrm{Sm}_{1--\mathrm{O}} \mathrm{O}_{\mathrm{y}} \\
(\mathrm{x} \sim 0,8 / \mathrm{y} \sim 1,9)\end{array}$ & LSGMC & $\begin{array}{l}\mathrm{La}_{\mathrm{x}} \mathrm{Sr}_{1-\mathrm{x}} \mathrm{Ga}_{\mathrm{y}} \mathrm{Mg}_{1-\mathrm{y}-\mathrm{z}} \mathrm{Co}_{\mathrm{z}} \mathrm{O}_{3} \\
(\mathrm{x} \sim 0,8 / \mathrm{y} \sim 0,8 / \mathrm{z} \sim 0,085)\end{array}$ \\
\hline \multirow[t]{2}{*}{ CaSz } & $\mathrm{Zr}_{0,85} \mathrm{Ca}_{0,15} \mathrm{O}_{1,85}$ & YDC & $\begin{array}{c}\mathrm{Ce}_{\mathrm{x}} \mathrm{Y}_{1-\mathrm{x}} \mathrm{O}_{\mathrm{y}} \\
(\mathrm{x} \sim 0,8 / \mathrm{y} \sim 1,96)\end{array}$ & LSGMF & $\begin{array}{c}\mathrm{La}_{\mathrm{x}} \mathrm{Sr}_{1-x} \mathrm{Ga}_{\mathrm{y}} \mathrm{Mg}_{1-y-z-z} \mathrm{Fe}_{\mathrm{z}} \mathrm{O}_{3} \\
(x \sim 0,8 / y \sim 0,5 / z \sim 0,4)\end{array}$ \\
\hline & & $\mathrm{CDC}$ & $\begin{array}{c}\mathrm{Ce}_{\mathrm{x}} \mathrm{Ca}_{1-\mathrm{x}} \mathrm{O}_{\mathrm{y}} \\
(\mathrm{x} \sim 0,9 / \mathrm{y} \sim 1,8)\end{array}$ & LSGMCF & $\mathrm{La}_{0,8} \mathrm{Sr}_{0,2} \mathrm{Ga}_{0,32} \mathrm{Mg}_{0,08} \mathrm{Co}_{0,2} \mathrm{Fe}_{0,4} \mathrm{O}_{3}$ \\
\hline
\end{tabular}

Isso significa que para cada mol do dopante $\left(\mathrm{Y}_{2} \mathrm{O}_{3}\right)$ é criada uma vacância de oxigênio duplamente ionizada $\left(\mathrm{V}_{\mathrm{o}}^{*}\right)$. Além disso, a adição de ítria a zircônia gera uma microestrutura com grãos extremamente finos e com excelentes propriedades mecânicas.

A fase cúbica da zircônia ocorre de 2370 a $2680{ }^{\circ} \mathrm{C}$, no entanto, com adição de óxidos como óxido de magnésio $(\mathrm{MgO})$, óxido de cálcio $(\mathrm{CaO})$, ítria e céria $\left(\mathrm{CeO}_{2}\right)$, essa fase pode permanecer estável a temperaturas inferiores, possibilitando que ela esteja presente nas temperaturas de operação da SOFC $\left(600-1000^{\circ} \mathrm{C}\right)$ [27].

Sistemas contendo de 8 , a $8,5 \mathrm{~mol} \%$ de ítria são caracterizados por uma condutividade iônica elevada $(0,18$ S.cm ${ }^{-1}$ a $1000{ }^{\circ} \mathrm{C}$ e $0,052 \mathrm{~S} \mathrm{~cm}^{-1}$ a $800{ }^{\circ} \mathrm{C}$ ). No entanto, sistemas de YSZ com cerca de $3 \mathrm{~mol} \%$ de ítria vem sendo utilizados devido a sua alta resistência mecânica (aproximadamente $1000 \mathrm{MPa}$ a temperatura ambiente), embora sejam caracterizados por baixa condutividade iônica, cerca de 3 vezes menor que no primeiro caso [28].

Materiais de eletrólito a base de cério como a céria dopada com gadolínio (GDC), céria dopada com samário (SDC) e céria dopada com cálcio (CDC), têm condutividade maior que eletrólitos a base de zircônio. Entretanto eles tendem a desenvolver condutividade eletrônica em atmosfera redutora. Além disso, entre a céria dopada e a zircônia (utilizada no ânodo) existe a tendência de formação de soluções sólidas a temperaturas de $1200{ }^{\circ} \mathrm{C}$, com condutividade iônica muito menor que aquela observada em eletrólitos de zircônia.

Mesmo não constando na tabela, o óxido de bismuto dopado também pode ser utilizado devido sua alta condutividade iônica quando comparado com a zircônia dopada. Entretanto esse material é de fácil redução, alta reatividade e baixa resistência, comprometendo a sua utilização [29]. São apontados também como materiais de eletrólito em SOFCs uma família de condutores iônicos a base de galato de lantânio $\left(\mathrm{LaGaO}_{3}\right)$. Em materiais onde o La é substituído pelo $\mathrm{Sr}$ e o Ga pelo $\mathrm{Mg}$ (LSGM) foi observada uma elevada condutividade iônica $\left(\sim 0,17 \mathrm{~S} . \mathrm{cm}^{-1}\right.$ a $800{ }^{\circ} \mathrm{C}$ ) tanto em atmosfera redutora quanto oxidante e coeficientes de expansão térmica compatíveis com os demais componentes da célula. Além dessas características esse composto também apresenta número de transporte iônico muito elevado. $\mathrm{O}$ grande problema com os materiais a base de lantânio, é que eles são instáveis em atmosfera redutora, sendo observado a perda de Ga tanto no galato de lantânio dopado quanto no puro. O Ga é perdido pela difusão de íons gálio através do material e por vaporização do óxido de gálio na sua superfície [30].

\section{Interconectores}

Os interconectores têm como função transferir os elétrons entre as células unitárias, fazer a separação entre comburente e combustível, além de dar estabilidade mecânica à célula. Em modelos planos de SOFC, os interconectores são responsáveis pelo fluxo tanto do gás combustível como do comburente, mantendo-os isolados um do outro. [31].

Dentre todos os componentes de uma célula a combustível, os interconectores estão sujeitos às mais severas condições durante o período de operação e, portanto, devem atender aos mais rigorosos requisitos para o seu bom funcionamento. Entre eles podemos citar: alta resistência à oxidação e redução em altas temperaturas, permanecer estável em contato com gases quimicamente diferentes, alta condutividade elétrica, alta densidade, elevada condutividade térmica facilitando as reações de reforma no ânodo e impermeabilidade gasosa [7].

As pesquisas com possíveis materiais que possam ser empregados como interconectores têm se concentrado nas últimas décadas em óxidos de terras raras. Entretanto, poucos óxidos podem satisfazer os rigorosos requisitos deste componente, sendo que os possíveis materiais são a cromita de ítrio $\left(\mathrm{YCrO}_{3}\right)$ e a cromita de lantânio $\left(\mathrm{LaCrO}_{3}\right)$ [28]. 
Entre os elementos dopantes da cromita de lantânio podemos incluir o cobalto, ferro, níquel, magnésio, cobre, estrôncio, cálcio e vanádio [6]. A cromita de lantânio é um condutor do tipo p; sua condutividade esta relacionada a um pequeno salto na polarização que ocorre quando a célula é aquecida da temperatura ambiente até $1400{ }^{\circ} \mathrm{C}$ a baixas pressões parciais de oxigênio $\left(10^{-18} \mathrm{~atm}\right)$. A condutividade desse material pode ser aumentada quando íons de valências menores (Ca, $\mathrm{Mg}$, $\mathrm{Sr}$, etc) substituem o $\mathrm{La}^{3+} \mathrm{Ou} \mathrm{Cr}^{3+}$. Em geral os problemas mais comuns com os interconectores à base de cromitas de lantânio estão relacionados ao alto custo do material, problemas de sinterização e empenamentos [32].

Além dos materiais cerâmicos, os metais e as ligas metálicas são considerados uma boa opção para serem utilizados como interconectores, devido a fatores como baixo custo, resistência mecânica, tecnologia de fabricação já bem determinada, além de apresentarem alta condutividade elétrica e térmica e não serem condutores iônicos. Entretanto muitos metais, ou mesmo as ligas metálicas possuem coeficientes de expansão térmica muito superior aos dos outros componentes da célula, além de apresentarem problemas relacionados à corrosão devido às altas temperaturas de operação das SOFCs [7, 31].

Dessa maneira somente ligas que se oxidam a temperaturas muito elevadas podem ser utilizadas. Dentre elas, podemos citar aquelas contendo $\mathrm{Cr}$ e/ou $\mathrm{Al}$, com a formação de uma camada protetora de um óxido $\left(\mathrm{Cr}_{2} \mathrm{O}_{3}\right.$ ou $\left.\mathrm{Al}_{2} \mathrm{O}_{3}\right)$. Contanto que as temperaturas de operação das SOFCs sejam inferiores a $800{ }^{\circ} \mathrm{C}$, alguns aços inoxidáveis têm sido usados, devido aos seus baixos custos e coeficientes de expansão térmica compatível com a zircônia. Nesse caso também há a formação dos óxidos de cromo e/ou alumínio. Entretanto, para os aços inoxidáveis a resistência à corrosão varia substancialmente com a composição da liga (concentração de $\mathrm{Cr}$ e/ou $\mathrm{Al}$ ou de outros elementos presentes) [28].

$\mathrm{O}$ maior problema com a formação da camada protetora de $\mathrm{Cr}_{2} \mathrm{O}_{3}$ a partir do $\mathrm{CrO}_{3}$ (resultante da reação do cromo com oxigênio) ou do $\mathrm{Cr}(\mathrm{OH})_{2} \mathrm{O}_{2}$ (resultante da reação do cromo com a água) é que a pressão de vapor do $\mathrm{Cr}^{6+}(\mathrm{g})$, pode ser significante nas temperaturas de funcionamento das SOFCs. Essas espécies podem interagir com a manganita de lantânio $\left(\mathrm{LaMnO}_{3}\right)$, material geralmente usado como cátodo, levando a uma mudança na sua composição de $(\mathrm{LaSr}) \mathrm{MnO}_{3}$ para $(\mathrm{LaSr})(\mathrm{MnCr}) \mathrm{O}_{3}$, além da formação de novas fases como $(\mathrm{CrMn})_{3} \mathrm{O}_{4}$ [28].

Além disso, estas espécies podem competir com o oxigênio na reação de redução levando a deposição do $\mathrm{Cr}_{2} \mathrm{O}_{3}$ na interface cátodo eletrólito (equações $\mathrm{G}$ e $\mathrm{H}$ ). Isto tem como efeito, uma diminuição do desempenho do cátodo bloqueando os sítios ativos onde ocorrem as reações de redução do oxigênio.

$$
2 \mathrm{CrO}_{3}+6 \mathrm{e}^{-} \rightarrow \mathrm{Cr}_{2} \mathrm{O}_{3}+3 \mathrm{O}^{2-}
$$

ou

$$
2 \mathrm{Cr}(\mathrm{OH})_{2} \mathrm{O}_{2}+6 \mathrm{e}^{-} \rightarrow \mathrm{Cr}_{2} \mathrm{O}_{3}+2 \mathrm{H}_{2} \mathrm{O}+3 \mathrm{O}^{2-}
$$

Por sua vez, a alumina $\left(\mathrm{Al}_{2} \mathrm{O}_{3}\right)$ é capaz de fornecer uma melhor proteção à superfície da liga, porém, é isolante, reduzindo a capacidade de condução de corrente no interconector, e com isso diminuindo substancialmente o desempenho da célula [28].

Todos os materiais até agora estudados para a confecção de interconectores exibem prós e contras com relação à sua utilização, pois não existe ainda um material que possa atender todas as exigências necessárias, fazendo com que as pesquisas no sentido de se obter um material adequado continuem.

\section{Selantes}

Os selantes são responsáveis pela vedação das células unitárias, impedindo a mistura do comburente com o combustível, além de conectar os interconectores à célula. Os requisitos que este componente deve atender são bastante rigorosos. Dentre eles podemos citar: isolamento elétrico, coeficiente de expansão térmica compatível com os demais componentes e estabilidade física e química a altas temperaturas. Os interconectores devem permanecer estanques durante a vida útil da célula (superior a 50.000 h) [28], conservarem-se fixos durante o período de operação, além de ligarem fortemente os componentes a serem conectados [7].

Os materiais mais comumente empregados como selantes em SOFCs são os vidros e compósitos vitrocerâmicos, pois estes materiais têm demonstrado que podem resistir a mais de 1000 h de operação da célula sem degradação significativa [33]. Os mais empregados são os vidros contendo óxidos de $\mathrm{Sr}, \mathrm{La}, \mathrm{Al}$ e $\mathrm{Li}\left(\mathrm{SrO}-\mathrm{La}_{2} \mathrm{O}_{3}-\mathrm{Al}_{2} \mathrm{O}_{3}-\mathrm{Li}_{2} \mathrm{O}_{3}-\mathrm{SiO}_{2}\right)$, silicatos alcalinos e alcalinos terrosos, além dos borosilicatos alcalinos [22].

A principal vantagem dos selantes vítreos é que a composição do vidro pode ser controlada com o objetivo de melhorar as propriedades do material. Entretanto, alguns problemas são associados a sua utilização como, sua natureza frágil e reatividade com os demais componentes nas condições de operação da célula. Para aplicações em SOFCs, os vidros a base de metais alcalinos terrosos são usados com maior freqüência. Dois critérios importantes para a seleção de um selante de vidro são as temperaturas de transição vítrea $(\mathrm{Tg})$ e os coeficientes de expansão térmica. A temperatura de transição vítrea é importante porque o vidro deve fluir de tal forma que forneça uma selagem adequada, mantendo ao mesmo tempo, rigidez suficiente para sustentar sua integridade mecânica. Assim, como no caso dos interconectores, a determinação de um material que atenda a todas as exigências necessárias a esse componente deve ser um dos focos de pesquisa na área de materiais usados em SOFCs [34].

\section{CONCLUSÕES}

Os materiais usados na confecção do ânodo, cátodo, eletrólito, interconectores e selantes, têm grande influência sobre o desempenho dos mesmos. Embora as pesquisas com 
esses materiais ainda estejam sendo realizadas, existem alguns materiais que têm se destacando por melhor atenderem aos requisitos relacionados ao componente que constituem. No ânodo, o composto NiO/YSZ é mais empregado devido principalmente ao seu baixo custo e sua estabilidade em atmosfera redutora. No cátodo, utiliza-se principalmente a LSM devido à compatibilidade existente entre o coeficiente de expansão térmica desse material e o coeficiente de expansão térmica do eletrólito geralmente composto por YSZ. Os interconectores por sua vez podem ser constituídos de materiais cerâmicos ou ligas metálicas sendo que, as ligas vêm sendo mais utilizadas devido, principalmente, ao baixo custo e sua alta condutividade elétrica e térmica. Como selantes, os vidros e compósitos vitrocerâmicos têm sido bastante usados, pois podem resistir a mais de $1000 \mathrm{~h}$ de operação da célula sem degradação significativa.

\section{AGRADECIMENTOS}

À CAPES e ao CNPq pelas bolsas concedidas.

\section{REFERÊNCIAS}

[1] A. B. Stambouli, E. Traversa, Renewable Sustainable Energy Rev. 6 (2002) 433.

[2] D. Simwonis, H. Thülen, F. J. Dias, A. Naoumidis, D. Sötver, J. Mater. Proc. Tech. 107 (1999) 92.

[3] Fuel Cell Handbook, U.S. Department of Energy, Office of Fossil Energy, National Energy Technology Laboratory, Morgantown, West Virginia, USA (2002).

[4] H. Wendt, M. Götz, M. Linardi, Química Nova 23, 4 (2000) 538.

[5] F. Calise, M. Dentice D'Accadia, A. Palombo, L. Vanoli, Energy 31 (2006) 3278.

[6] W. Z. Zhu, S. C. Deevi, Mater. Sci. Eng. 362 (2003) 228.

[7] K. C. Wincewicz, J. S. Cooper, J. Power Sources 140 (2005) 280.

[8] J. W. Yan, Z. G. Lu, Y. Jiang, Y. L. Dong, C. Y. YU, W. Z. Li, J. Electrochem. Soc. 149 (2002) 1132.

[9] N. Q. Minh, J. Am. Ceram. Soc. 76 (1993) 563.

[10] D. W. Dees, T. D. Clark, T. E. Easler, D. C. Fee, F.C. Mrazek, J. Electrochem. Soc. 134 (1987) 2141.

[11] X. Zhang, S. Ohara, R. Maric, K. Mukai, T. Fukui, H. Yoshida, M. Nishimura, T. Inagaki, K. Miura, J. Power Sources 83 (1999) 170.

[12] A. Atkinson, S. Barnett, R. J. Gorte, J. T. S. Irvine, A.
J. Mcevoy, M. Mogensen, S. C. Singhal, J. Vohs, J. Nature Mater. 3 (2004) 17.

[13] R. Gorte, S. Park, J. Vohs, C. Want, Adv. Mater. 12 (2000) 1465.

[14] M. M. G. Cuenca, Novel Anode Materials for Solid Oxide Fuel Cells, Tese de Doutorado, Un. Twente, Holanda (2002).

[15] F. H. Wang, R. S. Guo, Q. T. Wei, Y. Zhou, H. L. Li, S. L. Li, Mater. Letters 58 (2004) 3079.

[16] E. Maguire, B. Gharbage, F. M. B. Marques, J. A. Labrincha, Solid State Ionics 127 (2000) 329.

[17] H. K. Woodward, A performance based multi-process cost model for solid oxide fuel cells, Dissertação de Mestrado, Worcester Polytechnic Institute (2003).

[18] J. M. Ralph, J. A. Kilner, B. C. H. Steele, Mater. Res. Soc. Symp. Proc. 575 (2001) 309.

[19] T. Ishihara, S. Fukui, H. Nishiguchi, Y. Takita, J. Electrochem. Soc. 149, 7 (2002) 823.

[20] T. Hibino, A. Hashimoto, M. Suzuki, M. Sano, J. Electrochem. Soc. 149 (2002) 1503.

[21] N. T. Hart, N. P. Brandon, M. J. Day, N. Lapenã-Rey, J. Power Sources 106 (2002) 42.

[22] D. Z. de Florio, F. C. Fonseca, E. N. S. Muccillo, R. Muccillo, Cerâmica 50, 316 (2004) 275.

[23] T. He, Z. Lu, L. Pei, X. Huang, Z. Liu, W. Su, J. Alloy, Compoun. 333 (2003) 231.

[24] S. P. S. Badwal, F. T. Ciacchi, D. Milosevic, Solid State Ion. 91 (2000) 136.

[25] S. Nessaraj, A. Raj, R. Pattabiraman, Transactions SAEST 34 (2001) 89.

[26] E. Ivers-Tiffée, A. Weber, D. Herbstritt, J. Eur. Ceram. Soc. 21 (2001) 1805.

[27] S. Tekeli, M. Erdogan, B. Aktas, Mater. Sci. Eng. 386 (2004) 1.

[28] S. P. S. Badwal, Solid State Ionics 143 (2001) 39.

[29] S. P. S. Badwal, K. Foger, Ceram. Int. 22 (1996) 257.

[30] K. Yamaji, N. Negishi, T. Horita, N. Sakai, H. Yokokawa, XII Int. Conf. Solid State Ionics, Halkidiki, Grécia (1999) 166.

[31] S. P. S. Badwal, K. Foger, Mater. Forum. 21 (1997) 187.

[32] Z. Yang, J. Stevenson, P. Singh, Adv. Mater. Process 161 (2003) 34.

[33] R. Barfod, S. Koch, Y. L. Liu, P. H.Larsen, J. Electrochem. Soc. 1158 (2003) 2003.

[34] J. W. Fergus, J. Power Sources 147 (2005) 46.

(Rec. 10/03/2008, Rev. 10/07/2008, Ac. 12/07/2008) 